\title{
Incidental gastrointestinal stromal tumor during the sleeve gastrectomy
}

\author{
Hasan Elkan, (1) Mehmet Patmano, (1) Durmuş Ali Çetin \\ Department of General Surgery, Şanlıurfa Training and Research Hospital, Şanlıurfa, Turkey
}

\begin{abstract}
Today, obesity is an epidemic problem, especially in developed countries, and it is the second most common preventable disease after smoking that causes death. Surgical treatment is an appropriate and effective option in the treatment of this endemic disease which causes premature deaths with comorbidities. Gastrointestinal stromal tumor (GIST) is the most common mesenchymal tumor originating from the wall of the gastrointestinal tract. The annual incidence of GIST is reported to be 6-15 per million. GIST may occur anywhere in the gastrointestinal tract, starting from the esophagus to the anus. It is most frequently settled in the stomach. In our case, we aimed to present a case of mesenchymal tumor incidentally detected during the sleeve gastrectomy.
\end{abstract}

Keywords: Gastrointestinal stromal tumor; obesity; sleeve gastrectomy.

\section{Introduction}

Today, obesity is an epidemic problem especially in developed countries and it is the second most common preventable disease after smoking that causes death. Obesity is considered as a chronic disease that directly affects life time and comfort. ${ }^{[1]}$ Obesity is rapidly increasing especially in young people and many chronic diseases as comorbidity are encountered at an earlier age. Venous circulatory disorders, coagulopathies and cardiac disorders, especially diabetes and hypertension, are the major ones. In $90 \%$ of patients non-alcoholic fatty liver and in $25 \%$ of non-alcoholic steatohepatitis are present. ${ }^{[2]}$ The increase in degenerative joint disease, colon and breast cancers can also be added to them. While $67 \%$ of the USA population is overweight or obese, this rate is $40-50 \%$ in most European countries. ${ }^{[3]}$ Sustainable diet has a very impor- tant role in the treatment of obesity, but it seems almost impossible to do this in advanced obesity. Obesity is a disease that should be struggled with because of the high cost of treatment with the comorbidities. Surgical treatment is an appropriate and effective option in the treatment of this endemic disease which causes early death due to its comorbidities. ${ }^{[4,5]}$ Surgical treatment of morbid obesity is called bariatric surgery. The majority of patients have no gastrointestinal complaints.

Gastrointestinal stromal tumor (GIST) is the most common mesenchymal tumor originating from the wall of the gastrointestinal tract. ${ }^{[6]}$ It originates from interstitial Cajal cells responsible for intestinal motor function. ${ }^{[7,8]}$ The annual incidence of GIST is reported to be 6-15 per million. ${ }^{[9,10]}$ GIST may occur anywhere in the gastrointestinal tract starting from the esophagus to the anus. It is most 
frequently settled in the stomach. ${ }^{[11]}$ In this case, we aimed to present a case of mesenchymal tumor incidentally seen during surgery.

\section{Case Report}

Fifty-year-old female was planned for sleeve gastrectomy due to morbid obesity. Body mass indeks (BMI) of the patient $50 \mathrm{~kg} / \mathrm{m}^{2}$. The patient had no active gastrointestinal complaints. The patient had not undergone upper gastrointestinal (GI) endoscopy. The patient, who was under medical treatment with a diagnosis of asthma, was planned for sleeve gastrectomy after consultation with the relevant departments. During the operation, approximately $1 \mathrm{~cm}$ submucosal lesion was found near the large curvature in the corpus (Fig. 1). It was evaluated as preop GIST. Surgical technique was not changed because the lesion would remain in the specimen during the routine sleeve gastrectomy procedure. The surgical procedure

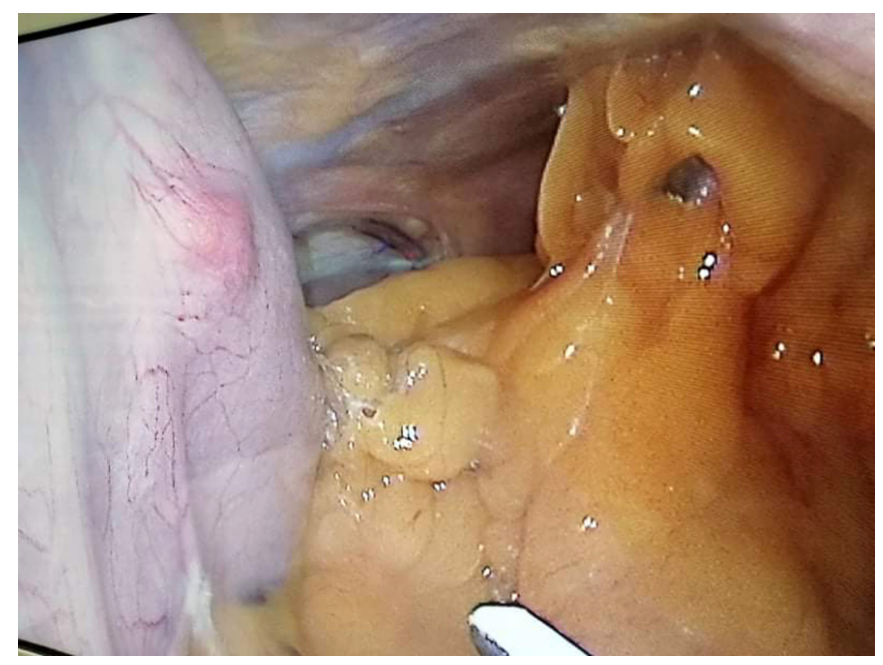

Figure 1. Surgical image (Submucosal lesion in the corpus).

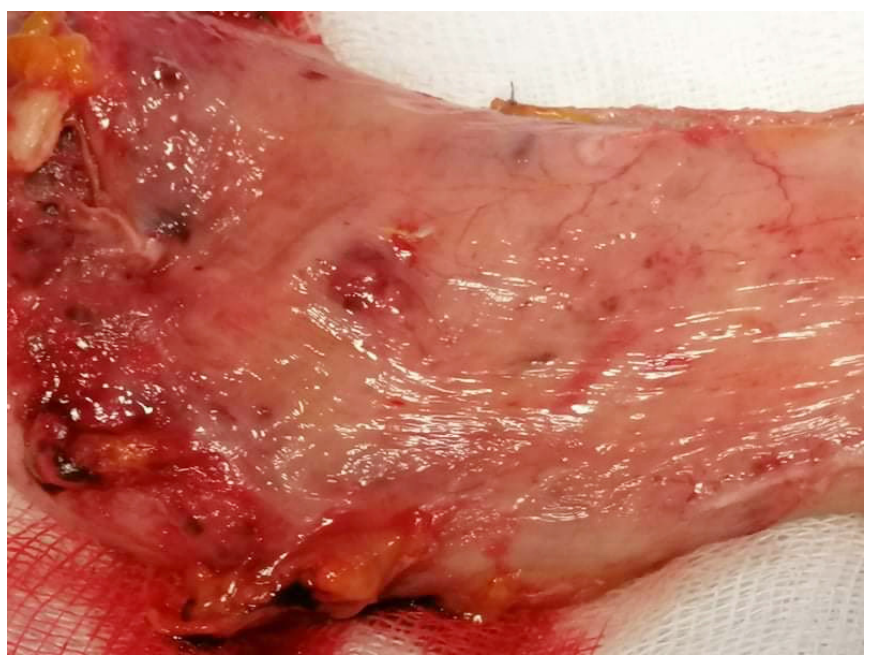

Figure 2. Spesmen image (Submucosal lesion in the corpus) was performed with the help of 5 trochars. Trochar entries were as follows; $10 \mathrm{~mm}$ from subxiphoid, umbilicus and right subcostal midclavicular line (for liver retractor), $12 \mathrm{~mm}$ from left subcostal midclavicular line (for stapler access), $5 \mathrm{~mm}$ from left subcostal midline axillary line. With the help of Covidien ${ }^{\circledR}$ ligasure, the large curvature was released starting from 4-6 cm distal of pylorus to the His angle. Then, with the help of a $38 \mathrm{~F}$ spark plug guidance, the stomach was resected including the fundus at a distance of 4-6 $\mathrm{cm}$ away from the pylorus. A narrow tubular stomach was created by this method. The lesion was taken out of the abdomen, the lesion was marked and was sent to the pathology (Fig. 2). Pathology result was revealed as spindle cell mesenchymal lesion. In the immunohistochemical staining of the preparations; CD117 was negative, DOG-1 was negative, SMA focal was positive, Desmin was negative, S100 was positive and Ki67 proliferation index was less than $1 \%$. Pathological results were reported as findings consistent with benign peripheral nerve sheath tumor with myxoid features. In the last 1.5 years, 240 patients underwent sleeve gastrectomy and one patient $(0.4 \%)$ was diagnosed with GIST. The patient was discharged on the fifth postoperative day, without any complications during and after the surgery. At the 6th month follow-up, the BMI was $38 \mathrm{~kg} / \mathrm{m}^{2}$ and there were no complications during the this period.

\section{Discussion}

Gastrointestinal stromal tumor (GIST) is the most common mesenchymal tumor originating from the wall of the gastrointestinal tract. ${ }^{[6]}$ Interstitial originates from Cajal cells. These cells are responsible for intestinal motor function. ${ }^{[7,8]} \mathrm{A}$ small proportion of these tumors have complete neural or smooth muscle differentiation; a large part shows a partial neural, ganglionic or mixed differentiation. ${ }^{[11,12]}$ The annual incidence of GIST is reported to be $6-15$ per million. [9,10] These tumors, which are usually asymptomatic, are diagnosed incidentally during radiological examination, endoscopy and surgery. In our patient, it was observed during surgery that did not give any syptom. The GIST may occur anywhere in the gastrointestinal tract starting from the esophagus to the anus. The most common place of involvement include; stomach (50-60\%), small intestine (25-30\%), esophagus (5\%), colon-rectum (5\%). ${ }^{[11]}$ Rarely, it can be seen in mesentery, peritoneum, omentum, and membranes of the abdominal organs such as liver, pancreas, ovaries and uterine organs. ${ }^{[10]}$ The most common metastasis sites of GISTs are liver and abdominal mem- 
branes (peritoneum, mesentery, omentum). The mean age of diagnosis was sixty, our patient was fifty years old..$^{[10]}$

A careful pathological study is required to differentiate GIST from lymphoma and carcinoma. Today, the most effective immunohistochemical method is the demonstration of KIT mutation known as CD117. The KIT protein is the receptor tyrosine kinase, which has a significant role in signal transduction in the cell membrane. Approximately $95 \%$ of GISTs are CD117 positive. In our case, CD117 was found as negative. Another immunohistochemistry indicator is CD34. CD34 is normally a protein which is expressed at hematopoietic precursor cells. CD34 positivity was the most important parameter for the diagnosis of GIST before the importance of KIT was defined. However, CD34 is not a specific indicator. $60-70 \%$ CD34 positivity can be detected. Ratio for the smooth muscle actin positivity is $30-40 \%$ and was found as negative in our case. ${ }^{[13,14]}$ The KIT negativity ratio is approximately $5 \%$ in GIST. The diagnosis of GIST in these patients is difficult. In other immunohistochemical analyzes, it is tried to be diagnosed by cell characteristics. In recent years, however, protein kinase $\mathrm{C}$ theta (PKC theta) has been shown to be highly expressed even in KIT negative tumors. ${ }^{[14]}$

Localized GIST treatment is surgery. Surgery is included in the standard treatment protocol of non-metastasized tumors. Complete surgical removal of the tumor is planned with the surgical treatment. In medical therapy, tyrosine kinase inhibitors are used. Imatinib is the first effective agent in GIST medical therapy. Sunitinib is a tyrosine kinase inhibitor. Nilotinib is a new tyrosine kinase inhibitor which has been shown to induce Bcr-Abl fusion gene inactivation in CML. Sorafenib is an inhibitor of multirosine kinase. Everolimus is an inhibitor of mTOR kinase (Mammalian Target Of Rapamycin). Perifosine inhibits activation of the Akt pathway. Motesanib is a multi-tyrosine kinase inhibitor. IPI504 is a molecule that targets heat shock protein 90 (Hsp90). Vatalanib is an inhibitor of oral multityrosine kinase (VEGFR1-2-3, KIT, PDGFR). Masatinib is an inhibitor of tyrosine kinase, which has been shown to be more effective than imatinib in patients without mutation or with mutations in the juxtramembrane region of KIT receptor tyrosine kinase. ${ }^{[15]}$ In our patient, because of the diagnosis of peripheral nerve sheath tumor with benign character, surgical treatment was found to be sufficient. No medical treatment was given.

In conclusion; mesenchymal tumors with benign potential should be kept in mind in the differential diagnosis of submucosal mass lesions of the stomach. The definitive diagnosis is made by histopathological and immunohistochemical examination. Nowadays, minimally invasive methods are successfully used in surgical treatment of mesenchymal tumors. Surgical resection with negative surgical margins is the treatment of choice in mesenchymal tumor lesions.

Financial Disclosure: The authors declared that this study has received no financial support.

Peer-review: Externally peer-reviewed.

Conflict of Interest: None declared.

\section{References}

1. Janssen I, Katzmarzyk PT, Ross R. Body mass index, waist circumference, and health risk: evidence in support of current National Institutes of Health guidelines. Arch Intern Med 2002;162:2074-9. [CrossRef]

2. Luyckx FH, Scheen AJ, Lefèbvre PJ. Non-alcoholic steatohepatitis. Lancet 1999;354:1298-9. [CrossRef]

3. Nuttall FQ. Body Mass Index: Obesity, BMI, and Health: A Critical Review. Nutr Today 2015;50:117-28. [CrossRef]

4. Adams TD, Gress RE, Smith SC, Halverson RC, Simper SC, Rosamond WD, et al. Long-term mortality after gastric bypass surgery. N Engl J Med 2007;357:753-61. [CrossRef]

5. Schauer PR, Kashyap SR, Wolski K, Brethauer SA, Kirwan JP, Pothier $\mathrm{CE}$, et al. Bariatric surgery versus intensive medical therapy in obese patients with diabetes. $\mathrm{N}$ Engl $\mathrm{J}$ Med 2012;366:1567-76. [CrossRef]

6. Cetin DA, Ciyiltepe H, Aday U, Gundes E, Bozdag E, Uzun O. A rare submucosal gastric tumor: Gastric schwannoma. J Turgut Ozal Med Cent 2018;25:154-6. [CrossRef]

7. Joensuu $H$, Kindblom LG. Gastrointestinal stromal tumors-a review. Acta Orthop Scand Suppl 2004;75:62-71. [CrossRef]

8. Fletcher CD, Berman JJ, Corless C, Gorstein F, Lasota J, Longley BJ, et al. Diagnosis of gastrointestinal stromal tumors: A consensus approach. Hum Pathol 2002;33:459-65. [CrossRef]

9. Goettsch WG, Bos SD, Breekveldt-Postma N, Casparie M, Herings RM, Hogendoorn PC. Incidence of gastrointestinal stromal tumours is underestimated: results of a nation-wide study. Eur J Cancer 2005;41:2868-72. [CrossRef]

10. Nilsson $B$, Bümming $P$, Meis-Kindblom JM, Odén A, Dortok A, Gustavsson B, et al. Gastrointestinal stromal tumors: the incidence, prevalence, clinical course, and prognostication in the preimatinib mesylate era-a population-based study in western Sweden. Cancer 2005;103:821-9. [CrossRef]

11. van der Zwan SM, DeMatteo RP. Gastrointestinal stromal tumor: 5 years later. Cancer 2005;104:1781-8. [CrossRef]

12. Reith JD, Goldblum JR, Lyles RH, Weiss SW. Extragastrointestinal (soft tissue) stromal tumors: an analysis of 48 cases with emphasis on histologic predictors of outcome. Mod Pathol 2000;13:577-85. [CrossRef] 
13. Lev D, Kariv Y, Issakov J, Merhav H, Berger E, Merimsky O, et al. Gastrointestinal stromal sarcomas. Br J Surg 1999;86:545-9.

14. Lee JR, Joshi V, Griffin JW Jr, Lasota J, Miettinen M. Gastrointestinal autonomic nerve tumor: immunohistochemical and molecular identity with gastrointestinal stromal tumor. Am J
Surg Pathol 2001;25:979-87. [CrossRef]

15. Nowain A, Bhakta H, Pais S, Kanel G, Verma S. Gastrointestinal stromal tumors: clinical profile, pathogenesis, treatment strategies and prognosis. J Gastroenterol Hepatol 2005;20:818-24. [CrossRef] 